Canadian Journal of Family and Youth, 14(1), 2022, pp. 124-145

ISSN 1718-9748@ University of Alberta

http://ejournals, library,ualberta.ca/index/php/cify

\title{
No Young Carer left Behind: A Two-Phased Study to Understand and Address the Needs of Young Carers from Rural and Urban Communities Before and During COVID-19
}

\author{
Kristine Newman, Heather Chalmers, Yana Berardini, Arthur Ze Yu Wang, \\ Vivian Stamatopoulos and Michelle Lewis
}

\begin{abstract}
Canada has one of the largest cohorts of young carers aged 15 to 24 who provide unpaid care for a family member. Although the body of research on young carers is growing in Canada, knowledge on the experiences and needs of young carers living in remote and rural communities is almost absent. This study aimed to understand and address the needs of young carers in rural/remote communities to support our community partner's goal of expanding their resources and support of this underserved population. The study was conducted in two phases with the first phase being a needs assessment and the second phase addressed those needs. In Phase 1 (conducted preCOVID-19), three focus groups were conducted with young carers from rural and urban communities with 20 young carers participating in total. Six themes were identified: Internet Usage in Daily Life; Finding and Filtering Information; Concerns Related to Internet Use; Social and Mental Support; What Makes Caregiving More Challenging; and Designing Something to Make Caring Easier. During Phase 2 (conducted mid-COVID-19), 2 focus groups were held via Zoom for Healthcare with a mix of rural and urban young carers in each group. One of the focus groups was held with those under 18 years old and the other included those between 18 to 25 years old. Four themes were identified: Responses to Emergencies; Awareness of Emergency Planning; Potential Impact on Planned Behaviour; and Considerations and Suggestions for Improvement.
\end{abstract}

Keywords: young carers, rural youth, urban youth, internet use, emergency planning/preparedness

Dr. Kristine Newman is an Associate Professor at the Daphne Cockwell School of Nursing at Ryerson University in Toronto, Canada. Dr. Newman's research interests lie in three broad themes: (1) Knowledge Translation - Health Evidence, (2) Assistive Technologies to detect agitation in persons with dementia, and (3) Dementia: Awareness, Intergenerational relations, and caregivers. She has built a research program 
surrounding her expertise in gerontological nursing practice, and knowledge translation. Her knowledge dissemination involves an arts-based approach that makes research accessible and impactful to various audiences. Such projects include: Spare a Thought for Dementia (T4D) campaign (www.thoughtsfordementia.com) and Embody - Experiencing Dementia through New Media (https://toronto.ctvnews.ca/mobile/video?clipId=1520005). Major publications include: Newman, K., Bookey-Basset, S., Wang, A.H., Wang, A.Z.Y. (2019). Carers need care too: Recalling the experience of being a young female carer for a relative living with dementia. Perspectives 40(3), pp. 6-16; Newman, K., Wang, A.H., Wang, A.Z.Y., Hanna, D. (2019). The role of internet-based digital tools in reducing social isolation and addressing support needs among informal caregivers: A scoping review. BMC Public Health 19(1495). https://doi.org/10.1186/s12889-019-7837-3; and Newman, K. \& Wang, A.H. (2018). Promoting youth awareness and understandings of dementia. The Journal of Aging and Social Change 8(4), 93-102. doi:10.18848/2576-5310/CGP/v08i04/93-102.

Dr. Heather Chalmers, Department Chair and Associate Professor at Brock University, has been trained in a multi-disciplinary context; specifically, she has degrees in Physical Education, Business, Education, and Developmental Psychology. Prior to joining Brock University, she worked within community and governmental agencies. Given her varied educational and experiential background, she examines issues and experiences in childhood and adolescence from a varied perspective believing that a holistic examination of issues will allow for a deeper understanding and an increased likelihood of making positive impacts in the lives of young people. Dr. Chalmers continues to work closely with governmental, treatment, and youthserving community agencies to help policy makers and agencies integrate new knowledge into their programs and services.

Dr. Yana Berardini, PhD, Brock University: Her research examines mental health of at-risk youth. Her latest research explored self compassion in young caregivers, as well as the positive and negative impacts of the pandemic on youth's mental health and mental health service provision.

Arthur Ze Yu Wang's research interests are in the areas of public health, primary prevention approaches, nutrition, mental health, motivation, dopamine, and addiction. He primarily supports research projects at the Daphne Cockwell School of Nursing at Ryerson University in the areas of young caregivers/family caregivers in the context of COVID-19 and attitudes/empathy towards persons living with dementia. Other research he currently supports include projects looking at marketing/nutrition of superfoods, slash youth and the future of careers, dependents in Canadian insurance and government policy, and stigma among Chinese people/people that are perceived to look Chinese in the context of COVID-19.

Dr. Vivian Stamatopoulos holds a Master of Arts (Sociology) and Doctor of Philosophy from York University (Sociology). She is currently an Associate Teaching Professor with the Faculty of Social Sciences and Humanities at Ontario Tech University. Her research interests focus on child and youth-based caregiving (young carers), unpaid family caregiving and long-term care (LTC).

Michelle Lewis began her career as a Teacher and Instructional Coach in alternative education private schools for at-risk youth. This gave her a wealth of experience with meeting Ministry requirements and coaching others on compliance which opened the opportunity to provide consulting services for private schools in need of compliance and quality improvement. When the opportunity came to lead a grass-roots non-profit as the Executive Director, she met her calling. Growing up in a small, rural town, she experienced what little supports and awareness existed for children, youth and families in need. She is very grateful to be a part of such a unique organization - Young Caregivers Association - and to have a voice for the silent and vulnerable. 


\section{Introduction}

Responding to the needs of young carers, our academic team used a collaborative approach and worked with the Young Caregivers Association (YCA; a not-for-profit organization that has supported young carers for over a decade and has become nationally recognized as the leader in young carer advocacy, support, and programming) to support their vision of "a Canada where young caregivers and their families are recognized, supported and empowered to achieve their full potential." With roots in the Niagara region, they now offer services in more rural areas and recently began focusing on developing a national family caregiver strategy with other provincial family caregiving organizations across Canada. In particular, YCA wanted to reach and expand resources for young carers with special attention to young carers from remote and rural communities whose needs may differ from those in urban settings. YCA wanted to assess digitally mediated platforms and online networks as the logical next step in providing accessible and timely support. Newman, Wang, Wang, and Hanna's (2019) scoping review on the role of internet-based digital tools in reducing social isolation and addressing support needs among informal caregivers found that "interventions using existing internet-based digital tools ... can be a cost-effective and a convenient strategy for developing support programs to help informal caregivers form online communities, gain support from each other, and access resources" (p. 10). Internet-based interventions could promote well-being among informal caregivers and provide more positive health outcomes for those whom they care for (Newman et al. 2019, p.10, Newman, 2020). Newman and others' findings suggested that community agencies leverage digital tools to provide informal caregivers with informational support and resources to help reduce their social isolation. However, lack of access to high speed Internet remains a problem in many rural Canadian areas (Canadian Radio-television and Telecommunications Commission, 2020), and may affect young caregivers' ability to participate in real-time connections, while the benefits of asynchronous chat boards for this population have not been established. In addition, digital solutions are complicated by age and privacy issues among others factors to consider.

\section{Background}

In the province of Ontario alone, over half a million young carers (those under the age of 25 years) provide various forms of unpaid support including medical, physical, and emotional to a loved one such as a parent(s), grandparent(s), or sibling(s) (The Change Foundation, n.d.) who is living with a disability, addiction, chronic illness, and/or other experience that is impacting their mental and physical health/well-being. Young carers must juggle school, jobs, family, and social obligations in addition to their responsibilities to provide care. Caregiving responsibilities for a young carer is estimated to take up 14 to 27 hours per week, which is equivalent to a part-time job and it is no surprise that their unpaid contributions to caregiving results in an estimated $\$ 25,000$ to $\$ 50,000 \mathrm{CAD}$ in annual savings for the family and healthcare system through their unpaid caregiving (Chalmers, 2012; Stamatopoulos, 2018; YCA, 2020). Despite the growing number of children and grandchildren who must take on a caregiving role to support a loved one, young carers remain invisible to most Canadians (Burns et al., 2013; Chadi \& Stamatopoulos, 2017). This invis- 
ibility is the result of a lack of recognition and representation of young carers in key communications, legislation, policies, and plans in Canada related to unpaid caregiving. Federal programs such as the Caregiver Credit and the Compassionate Care Benefit are only intended for working adults, and Canada in general lacks the necessary policies to support young carers in schools and post-secondary institutions (Breen, 2016). Most recently, in Canada and around the world, COVID-19 has brought on rapid and significant hardships and changes to everyone's lives including mass unemployment (Nicola et al., 2020) and mental health challenges (i.e.,stress, social isolation, loneliness, anxiety [CAMH, 2020]). The Canada Emergency Response Benefit (CERB) did not consider the financial burdens of caregiving and only recently did a small taxable benefit become available to those who work less than $50 \%$ of the hours they regularly work due to caregiving responsibilities known as the Canada Recovery Caregiving Benefit (CRCB) (Government of Canada, 2020). Young carers are now facing unique challenges around the world including delayed access or provision of care resulting from fear of COVID-19 (Lazzerini et al., 2020), separation from loved ones who display COVID-19 symptoms (Government of Canada, 2020), as well as changes to school and social relationships as a result of policies and fears surrounding the virus (Cohen \& Bosk, 2020; Efuribe et al., 2020; Liang et al., 2020; Orgilés et al., 2020; Rundle et al., 2020). Although being a young carer can be a fulfilling and enriching experience that has its good and challenging moments, without appropriate and adequate support, young carers can experience "the young carer penalty," which includes short- and long-term harm to academic, personal, social, and professional development (Chalmers \& Lucyk, 2012). Lack of support contributes to stress and depression, low self-esteem, anxiety, loneliness and isolation, difficulty relating to peers, and even suicidal ideation among young carers (Chalmers \& Lucyk, 2012; Lakman et al., 2017; Lakman \& Chalmers, 2019; Stamatopoulos, 2018).

One significant gap in the existing literature on young carers living in Canada is knowledge pertaining to the experiences and needs of rural young carers. Research focused on young carers in rural contexts tends to have been conducted in the UK (Becker \& Becker, 2008) and Africa (e.g., Robson 2004, 2006; Cluver \& Gardner, 2007; Lachman et al., 2014; Skovdal, Ogutu, Aoro, \& Campbell, 2009), and findings from these studies are limited in their applicability to rural Canadian youth due to differing national services, geographies, family structures, and health issues examined. In the UK and Ireland, for example, young carers' various roles and contributions have been identified at the national level (whereas Canadian young carers have not) and have actively supported for over 25 years in the UK and Ireland. Young carers in the UK have specific legal rights, policies, and designated services designed to support young carers in various sectors that they have to navigate on their many roles including school systems, social service programs, and healthcare settings. In Australia, young carers have access to financial support via bursaries to stay in education. In contrast, Canada lacks policies and services designed specifically to support young carers. There are currently only three formal young carer programs in Canada: two in Ontario and one in British Columbia (Stamatopolous, 2018). Existing services are simply inadequate considering that an estimated 1.25 million Canadians between 15 to 24 provide care to a loved one. In perspective, less than $1 \%$ of young Carers are being supported through programming spec- 
ifically designed for them. Without support, young carers have increased likelihood of depression, anxiety, low self-esteem, peer rejection, loneliness, and educational challenges (Chalmers \& Lucyk, 2012; Lakman, Chalmers, \& Sexton, 2017; Lakman \& Chalmers, 2019).

This collaborative study involved two phases. Phase 1 was conducted pre-COVID-19 and consisted of a needs assessment and exploration of interaction with technology/digital spaces of young caregivers from both rural and urban communities using focus groups. Phase 2 was conducted in the midst of the pandemic and through collaborative efforts with our community collaborator, YCA, we decided to develop and evaluate a YouTube video on emergency planning/preparedness and the COVID-19 pandemic to timely support young carers' informational needs and raise awareness of their role in our communities among the general public.

\section{Methods}

Qualitative methods, specifically focus groups, were employed to address our research questions: How do young carers use technology in their daily life? How do those technologies help to support their caregiving needs? What digital tools can be developed to address their needs that currently do not exist? Focus groups were selected because they allow for the exploration of opinions and attitudes of the participants.

Phase 1 recruitment was conducted between July and August 2019, three focus groups with a total of 20 young carer participants were conducted with urban and rural youth ( 2 rural, 1 urban) between the ages of 12 and 25 .

During Phase 2, an animated video on emergency planning was developed between July and August, 2020 (youngcaregivers.ca/resources/emergency-planning/) with the services of an animation studio and collaborative feedback from the YCA's Youth Advisory Committee. The Youth Advisory Committee engages young caregivers from the Haldimand, Norfolk and Niagara Regions through informing the YCA's outreach and service strategies. The young caregivers are given a voice in helping themselves and their peers, which develops valuable leadership skills. They plan programming, share their expertise of the young caregiver experience, help build awareness, participate in research, and inform organizational decisions. For our project, they supported the development of the video's storyline and content to ensure the video was effective and comprehensive in addressing informational needs of young caregivers at this time while connecting them to the resources they need. The video was then posted on YouTube and evaluated for its usefulness and accessibility via two focus groups. Recruitment occurred between September and October 2020. The focus groups consisted of mixed rural and urban youth. One focus group included young carers between 12-17 (10 participants) and the other included those aged between 18-25 years of age (6 participants) with 16 participants in total.

The focus groups in Phase 1 and Phase 2 were divided by younger and older aged youth to facilitate increased comfort in sharing opinions and views (Krueger, 2014).

\section{Sample}

During Phase 1 and Phase 2, a purposeful sample was recruited through the YCA that 
serves various communities across Ontario. All participants had parental permission to be approached for research participation. Participants had parental (if under 18 years of age) consent and provided assent for participation.

\section{Procedure}

During Phase 1, focus groups were held in the partner agency's offices. A private room was secured so agency staff could not hear the discussion. Focus groups lasted between 40 and 50 minutes. Pizza and drinks were provided following each focus group. During Phase 2, recruitment was conducted via email and focus groups were held via Zoom for Healthcare that was provided by the YCA.

Focus groups in both phases followed a semi-structured design to allow for follow-up questions to fully explore areas of interest and the participants' responses. The same two members of the research team conducted all focus groups. Following the completion of each focus group, the discussion was transcribed, ensuring anonymity of the participants prior to the research teams review of the transcripts.

Data from each stage of the project were analyzed using thematic analysis and using an inductive approach (Braun \& Clarke, 2006; Thomas, 2006). The research team independently analyzed the data and then came together to discuss the findings and resolve any areas of disagreement.

\section{Results}

\section{Phase 1: Needs Assessment and The Role of Technology}

Six themes were identified during Phase 1: Internet Usage in Daily Life; Finding and Filtering Information; Concerns Related to Internet Use; Social and Mental Support; What Makes Caregiving More Challenging; Designing Something to Make Caring Easier. These results will be presented by highlighting differences between urban and rural settings.

\section{Theme 1: Internet Usage in Daily Life}

Results revealed that across both urban and rural settings, all participants had Wi-Fi connection and access to the internet through their phones, computers, or tablets. However, one striking difference was that in the urban group, everyone had data plans, whereas in the rural groups, almost no one had data. In the rural groups, participants reported data to be expensive and their data usage was not frequent, thus they mostly relied on $\mathrm{Wi}-\mathrm{Fi}$. The rural groups also discussed the unreliable nature of Wi-Fi related to poor connectivity and speed in certain parts of their home and school.

Across both urban and rural groups, participants used the Internet to get access to YouTube or social media (e.g., Instagram, Snapchat, Facebook). The rural pre-adolescents also used the app Tik-Tok as well as Netflix and Pinterest, whereas the rural adolescent group used Spotify (e.g., for 
music and podcasts). Interestingly, usage of Facebook differed based on rural versus urban settings. The urban participants used Facebook and Facebook messenger; however, the rural participants only used the Facebook Messenger app because, as rural adolescents reported, the original Facebook had too much negativity in it.

\section{Theme 2: Finding and Filtering Information}

Every focus group was asked about how they found and filtered information about caregiving, particularly online, but also in general. Results indicated that participants in both urban and rural settings used Google, but differences were apparent. For instance, the urban participants disclosed using Google, Siri, YouTube, Wikipedia (but many did not consider it a trustworthy source), as well as by asking friends and a parent. The pre-adolescent rural group also disclosed asking friends and family, but also reaching out to REACH Facebook page (which was a local help line that offered resources and links to websites). One participant also responded that they connected with their school principal, although this was because the school ran a young carer support group. The adolescent rural group liked to use YouTube, as their main source for gathering information for skills and caregiving. They also reported using Bing and Reddit. Overall, this indicated differences in preference and comfortability. While both groups relied on Internet and in-person resources, the rural groups used in-person interactions with a trusted adult (e.g., parents, medical professionals, principal) more, and their reliance on Google was mainly for the purposes to find entertainment or coping/distraction.

To filter information, participants used various strategies. Urban participants reported to look at the first Google search page and they considered '.org' URLs to be trustworthy (e.g., government agency). They also read the information to ensure it aligned with facts. The rural preadolescent group also looked for signs of credible sources by seeing what the website says and if the info is factual, but they also relied on parents (specifically a mother who worked at a local support networking system, called REACH). Rural adolescents double checked sources and look for signs of credibility such as a green lock symbol, the word 'verified', or the source (more trustworthy if created by a licenced professional associated with a well-known organization). Rural adolescents also relied on observation and practice, which meant that they wanted to get information in-person to complement online information. They also suggested talking to fellow caregivers or their local support program, friends, family members, or medical professionals.

\section{Theme 3: Concerns Related to Internet Use}

From urban's youth perspective, they reported that social media use can be addicting, not helpful, and untrustworthy. For instance, as one participant commented: “...it's addicting. Once you start-I know like Instagram, once I started going on Instagram more and I had the will to go on it whenever I could, it's just like now it's a habit." As a result, one participant reported to take breaks. "I take many breaks off of social media for myself. I stayed off snapchat and Instagram for a good while. Especially when I am camping or am away, I try to stay off of it and just take pictures and just that's it." They also reported social media to be unhelpful, as it could create an unhealthy 
medium for social comparisons, as one participant said: “...they [other people online] made you feel more like 'oh why are they better? Oh they look better, they can do this better, they look better, this and that'. It can also be a source for negative interactions. One participant spoke about people's ability to say things on the Internet, they cannot say in person. "... because there are so many cruel and unwanted people on there that can basically say whatever they want because again, they are not saying that to your face, they are not scared to say it because it doesn't affect them because like you can't see their face, like 'what are you going to do about it', right?" For rural preadolescent participants, social media was emotionally challenging because others can be insensitive to someone's needs. One participant reported:

I think one of the bad things about using the internet is that there is always going to be jokes out there and there is always going to be people who will say not so nice things about everything and say like 'oh you are just looking for attention' or something like that. But what if somebody actually needs the attention? There is always going to be someone who doesn't take it seriously.

Rural adolescents were worried about receiving judgements from others if they sought help for their loved one.

The issue of privacy also arose. When discussing their comfortability around sharing information on a private site, urban participants were weary of security and hacking online. One participant reported that:

Snapchat now has anything you send through messenger, they now have any photos you send, posts you shared, like everything you say. So, like they have everything you are talking about so some things are just too personal that you don't want to say that online because you don't know who could get that information. And like if you are talking to someone about something personal or something that you didn't tell anyone and you just getting too worked up about it and you need to talk to someone about it, it's kind of better to say it face-to-face...

Or as another participant put: "The Internet is a scary place. But like everything you say there can be opened by basically anyone." Rural adolescents also mentioned privacy issues, as one participant responded: "there is never no way of being truly secure in things like that [on the Internet]. Even if there was a website that was truly anonymous and stuff, there are still ways that they find out who you are." This showed that there was quite a great deal of suspicion around the internet that took away their intentions of sharing personal information on it. 


\section{Theme 4: Social and Mental Support}

When asked about the support they used, participants reported several sources they used to obtain social and mental support. Urban participants relied on friends, powerhouse staff and other young carers, and case workers. For self-help, they use apps (e.g., Spotify for music, podcasts, meditation) and books. Rural pre-adolescents relied on text messages or face-to-face meetings, google searches, and self-help activities such as making slime, doing crafts, and listening to music to de-stress.

More importantly was the issue of whether support was preferred face-to-face or online. For urban participants, it was dependent on the situation and past experiences. One participant reported, "depends what the problem is. Say I have a problem and I was really sad or something, I rather talk online because I don't know, it's like ... yea, you don't want someone watching you cry right? Cuz that [is] embarrassing," or as another one mentioned, "It kind of depends whether you want to talk to someone in person or over social media, depending on what you are talking about. Because, like uh... or like even some people are just really busy so they don't really have time to drive to different cities to talk to someone because I know at least in my school, all my friends live in different cities because my school takes people from the whole Niagara region." This was also evident among the rural pre-adolescent group, as they spoke about geographical distance or proximity of the person. "I like face to face but I also like texting because texting is sometimes easier if the person is far away and lives in Alberta, like my uncle does, and sometimes it's easier to talk face to face with my friends and my family that live close." Another participant spoke about their preferences for online communications:

So even though you know that something is true, what you are saying, you know you are saying the truth, but like online, it's like a 50-50 chance because you don't like saying things to people faces... so I know some people when they get shy when they have to talk about anything personal or something, they don't like doing it face-to face because then they have to see the person's reaction and like as they are saying it, they see their reaction. Some people, you could be saying something shocking, and people don't necessarily have a good first reaction. So, it could be scary for us cuz our nerves are just like "what if they don't like me because this happened, or what if they don't accept this cuz it's just our brains' natural instincts to be like 'what if'.

Rural pre-adolescent participants were similar to urban, as one said: "face to face to me is very intimidating. I feel like I have to have a certain facial expression and I have to keep eye contact, and I'm not always the best at that when I'm talking about awkward or difficult subjects to talk like that." Similarly, another participant reported: "yea and I can kind of express myself better in text messages because I know how to word it better. I have more time to think about what I'm going to say." Despite this, face-to-face was preferred over video chats platforms like Facetimes and Skype. Finally, rural adolescents mentioned receiving emotional support from fel- 
low caregivers, from REACH staff, teachers, family members and significant others. They also reported using certain apps to help them keep track of their mood, distress, or get distracted when they need a break. However, apps had a limitation to them. For instance, one participant said, "I found it [app for depression and mood tracking] interesting, but it didn't really do much to actually help with my depression. It's just kind of helped me understand a little bit more what it was doing to me, and not how I could fight it," to which another participant responded, "... I've never found a tool with technology that really helps."

\section{Theme 5: What Makes Caregiving More Challenging}

When asked what makes caregiving more challenging, across all groups, school was the most reported challenge. Several young carers reported being overburdened with other responsibilities aside from caregiving. For urban participants, having extracurricular activities, on top of jobs and school and coordinating schedules with others, was tough. Some also reported being in a transition place where they finished school and were ready to look for employment. This was similar across rural pre-adolescents who also mentioned being in a transition as they finished middle school and were about to start high school. They also reported pressures from schoolwork and caregiving, as one participant noted:

For me, when it gets hard, well like when September comes, it gets hard, because when it comes... when school starts and everything, it starts getting into the middle to the end of September, it starts getting serious and everything. One of my moms have cancer and the other one has MS so then they are both going to appointment and then sometimes I have to be at school late or leave school early because I have to pick up and drop off my sister and she goes to [school's name], then I have to walk there when our moms aren't home so then it's hard because I have to then catch up with school work and stay. Sometimes it's an ongoing thing and it's like stressful.

In a similar way, rural adolescents also reported school to be stressful because of the pressures of getting good grades to have a good future. Sometimes the pressures and workload became difficult and overburdened them, as one participant reported:

I had two-unit tests in one day and the next day I had another one for bio and then that day I had to do a project too. There were so much things going on at home for me and I literary couldn't handle it. It was so bad. And I did bad on all my tests too, which doesn't help because I do study and I try to get good grades but then it's just really difficult sometimes, you know?" 
To reiterate how difficult their situation is and what makes caregiving more challenging, another participant added:

Working! Having a job and then also to have to come home and worrying about what's happening at home when you are gone for like say eight hours of the day. Or you go to school and then you have work right after, and you don't get home until like... you leave at like seven in the morning and you don't get home until say 10 o'clock at night. Knowing what's happening that you are not there to see.

\section{Theme 6: Designing Something to Make Caring Easier}

The participants shared many ideas in terms of what can be designed to make caregiving easier. The urban participants reported that they would like apps that can be used to keep track of their schedules, learn new skills (e.g., how to change diapers), and track their moods. For example, one participant suggested: "If you have parent and you have to change diapers or something just specifically how to do it with respect and then as well as another part of the app could be like a mood tracker of how you are doing that day. A self-reflective basically." Similarly, they suggested Instagram videos that would show how other people deal with challenges (i.e., family matters). They noted the importance of having such visual material, as one participant noted:

...because getting a visual of something sometimes helps. Because then you can see what they are doing, because sometimes you don't always understand what they are talking about and you can do something wrong but you don't... like if they are showing a video of how to help someone in a state, you don't want to just be like 'yes', they said 'talk to them about it and try calming them down'. You don't want to be like 'you are angry'-you want to know how to talk to them not just like talk...

They also mentioned that they want these videos or materials to be simple and user-friendly, easy to locate (instead of searching the net), and free. They also preferred apps with daily topics to be discussed compared to a chatroom where, without a moderator, can dissolve rapidly and become inactive. Finally, the urban group raised a few concerns regarding age appropriateness and security.

Similar to the urban participants, rural pre-adolescents also suggested an Instagram page, that would include links to resources and supports, inspiration and motivational quotes, and a moderator, who would respond to questions or could be contacted for support. Like the urban participants, rural pre-adolescents also liked visual information, but they suggested a poster that would raise people's awareness of their situation. Moreover, they recommended a YouTube channel, where one main person would show how to do things and what to do in a given situation 
and other people could post their ideas in the comments below. With this idea, they raised concerns over the use of foul language and people writing insensitive things. Similar to the urban group, the pre-adolescents from the rural communities wanted a moderator for a group chat since it would be difficult to uphold conversations without one. Finally, they noted the importance of creating channels for different groups for different ages. For one participant, it was important to talk to another youth, over talking to adult strangers, as they commented:

I feel like I would have different kinds of groups, like youth and then adults because to me, speaking to adults is extremely intimidating and if I was put into a group chat with adults that I don't know, I wouldn't be as opened and honest as I would be with just youth. Because I feel like I could relate more with people closer to my age so there could be different age groups. There could be one for adults, or youth, teens, younger.... But obviously, it would be monitored by an adult or someone like that.

Finally, rural adolescents, like the urban group, did not want anything expensive, but they also preferred anonymity and/or privacy when sharing their stories or asking questions. They noted the importance of sharing stories with others and "comparing notes," to understand what others may go through. Unlike the other two groups, rural adolescents spoke about the care-recipients' needs. One participant urged for more understanding and sensitivity from the public towards the care recipient, as they discussed:

Oh, one thing I would find really helpful is not for the caregiver itself, it's just other people's opinions on it. When I'm at school, a lot of people are really judgemental towards the special needs kid and they make all these jokes. I used to be in math class and I would be sitting, and all these other people would be like 'oh you don't get this, are you autistic?', you know, those kind of jokes and they would really make me mad... one time I did call a kid out and I was 'okay, chill'. It didn't really work. They were like 'you can't handle a joke'. It always comes back to you. So I feel like if they had more... if people would be more understanding, then I feel like that would really help caregivers too because that way, we would not feel... I dunno... cuz it makes me feel really sad when people do that.

Another participant advised for tailoring and matching different support workers to each clients' unique disposition where they expressed:

I have to say from someone who actually enjoys their job and is willing to do the little extra to actually take care of whoever they are with. I know at my house, there is a bunch of people who come out from REACH. From those people from REACH, 
none of them can keep up with [brother's name], because he is like me. He is physically fit, and he is very active and he likes to be outside all the time. But none of them can keep up with that. None of them can jump on the trampoline with him. Right?

\section{Phase 2: Using Technology to Address Emergency Planning Needs}

During Phase 2, four themes were identified: Responses to Emergencies; Awareness of Emergency Planning; Potential Impact on Planned Behaviour; and Considerations and Suggestions for Improvement.

\section{Theme 1: Responses to Emergencies}

Participants talked about experiencing the following emergencies: medical emergencies, fire, power outage, and tornados. Young participants (12-17) from both rural and urban communities would depend on their parents, but knew they would get out of harm's way if an emergency of any kind were to occur by going outside and listening to their parents/adults. In contrast, older (18-25) young carers would have more responsibilities and would know what to do in almost every situation from experience.

This was especially true for medical emergencies and fires. As noted by one participant from a rural community: "Normally, for medical emergencies, we go to my grandparent's house or they come here while my mom is in the hospital and my dad takes her to the hospital and sits with her in the hospital for a bit." Another participant from a rural community recalled a recent experience:

Um, actually a scenario happened in the summertime this past summer. Our chimney caught on fire, so the first thing we did was get ready, get out of house, and put our shoes on because we knew we had time, but we still had to get out, just in case. Um, I grabbed the cat. My mom grabbed the dog. Once I got the cat and the dog, we went outside. We put the pets in the car, so we didn't have to worry about them running away and then my step-dad put out the fire because it wasn't a big one, it was simple, and we waited outside until the fire department came. My grandparents also had to get out because we live with them, they live in the basement.

Older young carers from both communities had a mental checklist of what to do in a medical emergency to determine whether or not emergency services would be needed. They had significantly more responsibilities and would also be the person to call emergency services and provide them with information about their loved one.

Participants in rural communities tended to experience power outages significantly more 
than their rural counterparts leading to them having extra supplies in case it occurred. The outages in rural communities tended to last for long periods of time. Three participants in rural communities had flashlights, non-perishable food items, and a generator and two participants had small candles. Other supplies participants mentioned were a fireplace, blanket, and trailer. According to a participant from a rural community: "but like we have a lot of like cans and nonperishables and stuff like that for food-wise if we're stuck in the house. And then we have flashlights. And um blankets in case it gets like cold or whatever." In contrast, only one participant living in an urban community had supplies that included only non-perishable food items. The findings for the younger group were similar to the older group, but those in the older group would be the ones to keep inventory of medication and ensure non-perishable food was not expired. As one participant describes:

We have learned the hard way to make sure we have extra at all times. When something's running out we're always prepared and organized to go get it because there has been times where we've run out of something and with my mom not feeling well, it just causes her more pain and more struggle and then we're running around and and trying to scrape by, but the best thing with our situation, and caring for her, is to stay organized. So, I think um that's a really huge part about our emergency plan is staying organized.

Only the younger participants living in rural areas talked about their responses to tornados. Participants often knew to get to a safe place such as the cellar, basement, or washroom (if there was no basement). Parents would give focus on getting the person being cared for to safety and ensuring pets are safe. One participant said:

For like a more like weather emergency for like a tornado, we, we just go in the basement. Even if like I start seeing something I go into the basement normally because I get scared always with tornadoes and stuff, so I go to the basement, but my parents normally will stay up and then my mom will normally have to walk him down the stairs.

\section{Theme 2: Awareness of Emergency Planning}

There were distinct differences between the younger urban and rural groups when it came to awareness of the need to plan for emergencies. Four participants from urban communities, prior to watching the video, never considered emergency planning, but after watching the video they got a sense that an emergency could happen at any time. One participant from an urban community 
believed that most people already knew about emergency planning and the information in the video. Participants from rural communities generally had an emergency plan even if it was simple and only two participants reported not knowing what to do in an emergency. Two participants thought their plan might need some more work after watching the video.

Older participants from both communities were aware of everything mentioned in the video and thought the content was, at most, a reminder and is probably much more suited for a young audience.

\section{Theme 3: Potential Impact on Planned Behaviour}

For the younger group, those from urban communities wanted to make an emergency plan regarding who to contact in case of an emergency, particularly for medical emergencies and snow storm issues, and share the information with their family. "I know personally we never really talked about anything like this before, so after watching the video, probably I will talk to my parents about what to do in an emergency because the information is pretty helpful," said a participant from an urban community. Participants from rural communities wanted to make a go-bag and make their emergency plan more detailed by working with their families. Overall, young carers from both communities wanted to share what they learned with their families and thought that creating an emergency plan was important so that they do not panic.

Older participants from urban communities wanted to share the video with friends, make an emergency kit, and figure out what to do with their pets. Those from rural communities did not find the information too helpful in their situation because they already experienced it. That being said, one participant noted that she would make an emergency plan and post it in the home for personal support workers to follow when no she is not available to help and would share the video with her co-workers/clients:

I work for [an organization that supports people with disabilities], so this would be great to talk about with a client. Like a parents wouldn't be able to just have a conversation with their child, but to the parent: "Hey, You should look into this for your household. You might find this helpful." They might not even have thought about it, so this would be helpful when I'm having a meeting with a client. For sure.

Theme 4: Considerations and Suggestions for Improvement

Younger participants from both rural and urban wanted to see more detailed information and more colour. One participant added it would be helpful to mention to add some entertainment if people are making a go-bag. Another participant stated: 
Maybe add information like essential toiletries or something else like that because I think the main thing [in this video] is like things you need to survive like food, water, clothes, but other things that may come up, especially for like a caregiver, you might need things for whoever you're caring for, so maybe add a reminder to pack extra things like those other things as well.

One participant thought the video needed some words of encouragement and a reminder to stay calm because the video seemed alarming and made her feel like she needed to rush during an emergency. Participants also wanted to share the video with others outside their family, but were not sure on how to do so and wished the video specified how to share the video with others. As one participant from an urban community noted:

\begin{abstract}
"Yeah, um, I think it's a good video to share, but I'm not sure in what context you would share it because I personally wouldn't randomly be dropping it in a random conversation, but it does say in the video to share it with your friends, which is good, but I don't know if there would be a specific situation I would bring that up. Like it would be nice if the video told you how to share because it's like say hi, how are you, and then, like, oh, you want to see this video about emergency planning kits? So if there'd be more instruction on how to share it or if it'd be like telling you to share it through social media, other things like that.
\end{abstract}

For the older group, those from both communities thought that the video added very little value to an older audience and was definitely designed for a younger audience. Speaking from recall of their childhood, participants thought that younger caregivers would not be able to do much during an emergency without the help of an adult. They believed that knowing emergency contacts would be the most important thing to know for those who are younger and believed an emergency plan should be tailored to a person's age. Regarding making the content of the video more appropriate for older young carers, participants believed it would be important to include information regarding legal issues surrounding wills, estates, and power of attorney. As stated by one participant:

There's adult legalities that are important that you don't think about as a child, but when someone passes away, there's an estate, in some cases, like for me, I've been my mom's POA, since I was 19-20. Like for many people, that's very young to be going through all that and I know there's people out there that are even younger than that and that's the point of contact, their power of attorney, is just a young person 18 years old. Of course, I know people younger than that who have an exec- 
utor but like when you're younger, it's a little hard to navigate with that side of things, so it's good to have, of course, an emergency contact. But I think it's also important to treat like those young people, the pre-teenagers, and young adults should be able to know like the system and also know how things work and that sort of case too. Because there's a lot of things that, I guess, when you're emotional and you lost a parent, you don't think straight but there's also things that have to happen legally as well.

Although links to resources were placed at the end of the video, the participants believed that it should be made more visible. One participant from a rural community recommended the creation of a checklist of questions on the web page with resources (managed by the YCA) for young carers to answer with their family, which was met with agreement from other participants as a good idea: "Yeah, just to an example page or just even just like a question. Do you have, who is your point of contact and emergency? Or you could write it easier for a child, of course. And where his mom's medication at? Ask mom is it locked up? Where's the key to it? Things like that." She also recommended creating more complex questions for older young carers.

\section{Discussion}

The purpose of this study was to explore the best way to use technology to support more young carers. Newman et al's (2019) review found that "social media platforms have a potential to address caregivers' needs in complement to other services" (p. 9). As found in this study, "caregivers often turn to internet-based platforms that offer anonymity, flexibility, and 24-h access from the comfort of their homes. These benefits are not offered by in-person support programs" (Newman et al., 2019, p. 9). However, accessibility is an issue, particularly with respect to rural youth. If there is online support and they can only access the internet through a free Wi-Fi site, privacy may be an issue. Further, trust with any online support can be an issue, as noted previously in results - young adult carers (18-25 years) indicated that they have distrust about confidentiality and security of the internet. Interestingly, there was more trust with younger participants in the study. Credibility of a site is critical for trust and as youth become older they develop the critical thinking skills and have better strategies to confirm the quality of information found on websites. Participants also stated that there was no consistency in the use of existing discussion forums such as Facebook and Reddit, among others, in terms of their internet safety concerns and drawbacks. Also relevant to today's world, participants had the concern of internet addiction.

We do not want to diminish the benefits of participating in the support programs offered by our partner agency. These benefits were evident as participants reported using strategies taught and supported by the programs offered, for instance, meditation, crafts, music to relax, etc. Plus, youth noted the importance of having a choice (or matching) with any support worker/online counselling as they must feel a connection that is similar to face-to-face settings.

Overall, anything that is developed electronically needs to be viewed as supporting/making caregiving more effective/efficient, such as, using online apps to track tasks, and learning new skills (e.g., how to change a diaper) especially with respect to their caregiving. Social media can 
be a viable means of connecting with young caregivers but the above discussed areas need to be thought about when using such platforms; especially when young carers live in urban versus rural areas. There were some limitations in the study such as, young caregivers are a diverse group with differing ages but we did not capture those younger than 12 (common for many studies); focus groups were recruited only from YCA where they already receive support; participants were limited to regions where YCA provides service; only conducted focus groups in English; and, gender based and intersection analysis was not used to maintain anonymity of the participant. Since the young caregivers were connected to YCA they had some practice speaking about their experiences (felt more comfortable) and provided us with rich discussions that informed our study.

\section{Outcomes}

Based on young carers' feedback and recommendations to develop resource videos, A YouTube video was created to be housed through the Young Caregivers Association's website [https://youngcaregivers.ca/resources/emergency-planning/]. We started with the timely topic of Emergency planning and preparedness, as requested by young carers, due to the Covid-19 pandemic. It should be noted that although this video and accompanying resources were created in response to COVID-19 pandemic, it included important general information regarding emergency planning and preparedness that could assist young carers (and others) in several different situations [https://youngcaregivers.ca/resources/emergency-planning/emergencyplanning-kits/].

\section{Conclusions}

Although this video and resource is available electronically, we need to address several assumptions that people seem to forget when face to face gatherings cannot occur. First, there is an assumption that everyone has the finances to afford internet, data access, or even an electronic device. Some examples are: (1) many people do not have a data plan and rely on free Wi-Fi access, (2) that everyone's data plan is unlimited, and (3) many people still do not own a mobile phone. This speaks to the inequality that is in our society where the more vulnerable are overlooked and it is just assumed everyone has equal access. Secondly, there are several other technical issues such as internet bandwidth and the fact that some areas in Ontario (and Canada) still use dial up. Yes, in 2020, there are individuals still using dial up! Moreover, some northern regions might not have access at all. Until better access to the internet is throughout our country, rural youth will be at a disadvantage compared to urban youth. These facts are not new news to Canadians, but people are forgetful of the privileges that they hold such as living in an urban location.

There is a place for technology, but it must be multi-faceted, hosted by a credible source 
and whatever electronic platform is developed needs to offer skill development and personal support to young carers. The research team hopes to build more useful YouTube videos and resources that can help support Young Carers in the future.

\section{Acknowledgements}

Thank you to all the young carer participants in the study. We would like to thank our partner the Young Caregivers Association for all their efforts in the project too. The study was funded by Social Sciences and Humanities Research Council, Partnership Engagement Grant and Faculty of Community Services, Ryerson University. The funding body had no role in study design, data collection; data analysis; writing the report or the decision to submit the manuscript for publication. University of Ontario Institute of Technology was not involved in Phase 2 of the study. Finally, we would like to formally thank all the essential workers who supported their communities during the Covid-19 pandemic - Thank you! 


\section{References}

Braun, V., \& Clarke, V. (2006). Using thematic analysis in psychology. Qualitative Research in Psychology, 3(2), 77-101.

Breen, A.V. (2016, April 5). It's time to care for our (young) carers. Retrieved from http://vanierinstitute.ca/time-care-young-carers

Burns, C. M., Abernethy, A. P., Dal Grande, E., \& Currow, D. C. (2013). Uncovering an invisible network of direct caregivers at the end of life: A population study. Palliative Medicine, 27(7), 608-615.

Canadian Radio-television and Telecommunications Commission. (2020, August 12). Broadband fund: Closing the digital divide in Canada. Retrieved from https://crtc.gc.ca/eng/internet/internet.htm

Centre for Addiction and Mental Health. (2020, September 23). Mental health and the COVID19 pandemic. Retrieved from https://www.camh.ca/en/health-info/mental-health-andcovid-19

Chadi, N., \& Stamatopoulos, V. (2017). Caring for young carers in Canada. Canadian Medical Association Journal, 189(28), E925.

Chalmers, H., \& Lucyk, L. (2012). The impact of caregiving: Is it who I am or what I do? Child and Youth Care Practice, 25(2), 37-46.

Cohen, R. I. S., \& Bosk, E. A. (2020). Vulnerable youth and the COVID-19 pandemic. Pediatrics, 146(1).

Creswell, J. W. (2007). Qualitative inquiry and research design: Choosing among five approaches ( $2^{\text {nd }}$ ed.). Sage Publications, Inc.

Efuribe, C., Barre-Hemingway, M., Vaghefi, E., \& Suleiman, A. B. (2020). Coping with the COVID-19 crisis: A call for youth engagement and the inclusion of young people in matters that affect their lives. Journal of Adolescent Health, 67(1), 16-17.

Government of Canada. (2020, October 17). Canada Recovery Caregiving Benefit (CRCB). Retrieved from https://www.canada.ca/en/revenue-agency/services/benefits/recoverycaregiving-benefit/crcb-who-apply.html

Krueger, R. A. (1994). Focus groups: A practical guide for applied research (2 ${ }^{\text {nd }}$ ed.) Thousand Oaks. CA: Sage. 
Krueger, R. A. (2014). Focus groups: A practical guide for applied research. Sage publications.

Lakman, Y. \& Chalmers, H. (2019). Psychosocial comparison of carers and non-carers. Journal of Child and Youth Services, 40(2), 200-219. https://doi.org/10.1080/0145935x.2018.1553614

Lakman, Y., Chalmers, H., \& Sexton, C. (2017). Young carers' educational experiences and support: A road map for the development of school policies to foster academic success. Alberta Journal of Educational Research, 63(1), 1-12.

Lazzerini, M., Barbi, E., Apicella, A., Marchetti, F., Cardinale, F., \& Trobia, G. (2020). Delayed access or provision of care in Italy resulting from fear of COVID-19. The Lancet Child \& Adolescent Health, 4(5), e10-e11.

Liang, L., Ren, H., Cao, R., Hu, Y., Qin, Z., Li, C., \& Mei, S. (2020). The effect of COVID-19 on youth mental health. Psychiatric Quarterly, 1-12.

Newman, K. (2020). Relevance of digitalization for informal caregivers to address support needs and reducing social isolation during the COVID-19 Pandemic. Journal of Aging Science, 8(4), 243.

Newman, K., Wang, A.H., Wang, A.Z.Y., Hanna, D. (2019). The role of internet-based digital tools in reducing social isolation and addressing support needs among informal caregivers: A scoping review. BMC Public Health. 19(1495) https://doi.org/10.1186/s12889-019-7837-3

Nicola, M., Alsafi, Z., Sohrabi, C., Kerwan, A., Al-Jabir, A., Iosifidis, C., ... \& Agha, R. (2020). The socio-economic implications of the coronavirus pandemic (COVID-19): A review. International journal of surgery (London, England), 78, 185.

Orgilés, M., Morales, A., Delveccio, E., Mazzeschi, C., \& Espada, J. P. (2020). Immediate Psychological Effects of COVID-19 Quarantine in Youth from Italy and Spain. Available at SSRN 3588552.

Rundle, A. G., Park, Y., Herbstman, J. B., Kinsey, E. W., \& Wang, Y. C. (2020). COVID-19Related School Closings and Risk of Weight Gain Among Children. Obesity, 28(6), 1008-1009.

Sexton, C. (2017). Caregiver stress: An exploration of stressors and coping strategies among young carers [Unpublished master's thesis]. Brock University.

Stamatopoulos, V. (2018). The young carer penalty: Exploring the costs of caregiving among a sample of Canadian youth. Child \& Youth Services, 21(2), 1-26. 
Thomas, D. R. (2006). A general inductive approach for analyzing qualitative evaluation data. American Journal of Evaluation, 27(2), 237-246.

Young Caregivers Association. (2020). Who are young caregivers?. Retrieved from https://youngcaregivers.ca/who-are-young-caregivers 